\title{
Some observations on endogeneity in the normal rate of capacity utilisation
}

\author{
Brett Fiebiger* \\ Independent analyst
}

\begin{abstract}
As is well known, the closure of the canonical Neo-Kaleckian model is an endogenous rate of capacity utilisation. To allay concerns of Harrodian instability one response has been to endogenise the normal rate to effective demand pressures. Recent contributions have stressed microfoundations for an adjustment in the normal rate towards the actual rate. The new approach focuses on shiftwork and redefines capacity utilisation as the average workweek of capital. This paper examines whether the new concept of capacity utilisation can provide a firmer basis for endogeneity in the normal rate. It argues that the assumption of variability in the normal shift system cannot be generalised across manufacturing industries, while the potential relevance for non-manufacturing industries is unknown. Another concern is that long-run trends in the average workweek of capital and aggregate demand do not coincide. The paper also finds that the long-run trend in the US Federal Reserve's index of capacity utilisation for the manufacturing sector is not flat as frequently claimed. Instead, there is a downward trend from the mid 1960s, which matches the slowdown in aggregate demand.
\end{abstract}

Keywords: Kaleckian, investment, capacity utilisation, normal rate of utilisation

JEL codes: $B 50, E 12, E 22$

\section{INTRODUCTION}

A long-standing debate in heterodox economics is whether the long run must be characterised by an equalisation between the actual and normal utilisation rates of productive capacity. A related debate starts from the premise that assuming such an equalisation is necessary, then is it the actual rate of capacity utilisation that must adjust to the normal rate, or vice versa? Harrodian authors, along with the Sraffians who write under the banner of the supermultiplier, have argued that the normal rate of capacity utilisation provides a centre of gravity. ${ }^{1}$ For these authors it is difficult to contemplate that capacity utilisation could be an endogenous variable in the long run. The persistent critique advanced is that the canonical Neo-Kaleckian model would be subject to Harrodian instability in the long run.

* Email: brett.fiebiger@hotmail.com.

1. For the Harrodian position, see Skott $(2012 ; 2019)$ and Skott and Zipperer (2012). For the Sraffian supermultiplier position, see Freitas and Serrano (2015), Pariboni and Girardi (2018) and Girardi and Pariboni (2019). There are also Sraffian authors who have argued for longrun endogeneity in the utilisation rate and reject the idea that the normal utilisation rate acts as a 'centre of gravity' - see Trezzini (1998), Palumbo and Trezzini (2003) and Smith (2012). 
Neo-Kaleckians have offered four different replies. ${ }^{2}$ One reply is to reject the relevance of long-period analysis. If the long period is a theoretical abstraction in logical time - with no counterpart in historical time - then the medium-run equilibrium of the Neo-Kaleckian model may provide a more realistic approximation to the real-world. ${ }^{3}$ A second reply situates the decisions that firms make on capacity utilisation in the context of other strategic goals and conflicting claims. Managers may have to accept an actual rate of capacity utilisation that differs from the normal rate as a trade-off to meeting other strategic goals either in full or in part (Dallery and van Treeck 2011).

A third reply is that the actual and normal rates of capacity utilisation could be equalised through an adjustment in the latter towards the former. Lavoie's (1995) rationale for such a scenario emphasised that decisions on the degree of idle capacity are a convention and partly responsive to effective demand pressures. The counter-view follows Kurz (1986) in arguing that the decision on the normal utilisation rate is based solely on cost-minimisation. Proponents and critics of this third reply could only agree to disagree. A new line of argument on endogeneity in the normal utilisation rate has shifted the focus to microeconomic foundations. Nikiforos $(2013 ; 2016$; 2018) claims that his approach is superior because it is consistent with cost-minimising microeconomic behaviour. Decisions on the normal shift system are argued to be of equivalent importance to the choice of production technique. In the micro model a representative firm chooses the normal utilisation rate - defined unconventionally as the average workweek of capital - to minimise costs / maximise profits.

A fourth reply is to modify the Neo-Kaleckian model. Lavoie (2016) obtains a longrun equality between the actual and normal utilisation rates by combining a Sraffian supermultiplier (SSM) adjustment mechanism with a weak Harrodian mechanism. The fourth reply has pleased SSM authors but not Skott (2019). Some Neo-Kaleckians are also displeased. Dávila-Fernández et al. (2019) point to Nikiforos $(2013 ; 2016)$ as a motivation for why endogeneity in the normal utilisation rate offers a more promising alternative. ${ }^{4}$ Pariboni and Girardi (2018) note that the authors, in altering Lavoie's (2016) model, forgot to include autonomous expenditures and that an inclusion would undermine the alternative adjustment process. Girardi and Pariboni (2019) focus on Nikiforos $(2013 ; 2016)$ in their critique of the proposition that the normal/ desired utilisation rate can be an adjusting variable in the long run.

This note examines the new 'microfoundations' case for endogeneity in the normal rate of capacity utilisation. The analysis proceeds in Section 2 with an overview of the theoretical arguments of the new approach. Nikiforos's (2013) micro model is discussed in Section 3. Section 4 considers the empirical evidence marshalled by Nikiforos (2016) and finds it lacking. Section 5 queries the claim that the US Federal Reserve's index of capacity utilisation exhibits a flat trend. The declining trend since the mid 1960s fits the slowdown in aggregate demand. Concluding remarks are presented in Section 6.

2. See Hein et al. (2012) for a discussion of the first three replies.

3. The concept of the 'medium run' (or the 'medium to long run') in Neo-Kaleckian models draws support from Caserta and Chick's (1997) notion of 'provisional equilibrium'. In the medium run the capital stock can adjust as in the long run. There is, however, no assumption that the economy will reach a fully adjusted position defined as when the actual utilisation rate is equal to the normal utilisation rate (Hein et al. 2012, pp. 145-146).

4. Dávila-Fernández et al. (2019) fail to discern that Lavoie's (2016) long-run model obtains an equality between the actual and normal utilisation rates due to the combination of autonomous or semi-autonomous expenditures, the Keynesian stability condition and a weak Harrodian mechanism. See Lavoie (2019) for a discussion. 


\section{CAPACITY UTILISATION, CAPITAL UTILISATION AND THE AVERAGE WORKWEEK OF CAPITAL}

Nikiforos (2018, p. 3) summarises his research as follows: 'I have argued that an endogenous rate of capacity utilization is consistent with a firm that minimizes its cost and that empirical evidence confirms such an endogeneity'. One caveat is that his preferred definition of capacity utilisation is an unconventional measure: 'the average time the capital stock is run during a certain period of time (e.g., how many hours per week out of the 168 that is maximum - a plant is running)' (ibid., p. 9). Nikiforos (2016) presents data on the average workweek of capital for US manufacturing firms from various authors. On these studies - with varying data sources and methodologies that cover a range from as early as 1929 but with annual observations starting only in the 1950s or 1970s and finishing in the 1980s or early 1990 s - he concludes that 'utilisation, aside from the expected pro-cyclical fluctuations, is far from stationary and has an upward trend over time' (ibid., pp. 449-450). His preferred interpretation of the upward trend is effective demand pressures. There is scope for other explanations (see Section 4).

In contrast to the average workweek of capital (AWC) it is claimed that the Federal Reserve's (Fed) 'index of capacity utilisation by construction gravitates around a structural exogenous level of utilisation and by construction is stationary' (ibid., p. 446, emphasis in the original) due to changes in the normal shift system. Section 5 argues that these claims are unpersuasive. Here it is sufficient to note that these claims form part of Nikiforos's (2016; 2018) rationale for adopting his preferred measure of the 'utilisation rate'. Three distinct concepts are referred to interchangeably as 'utilisation': (i) capacity utilisation; (ii) capital utilisation; and (iii) the AWC. A starting point, then, is to clarify these concepts.

It must be emphasised that the AWC - the hours per week that the plant is run - is different from the economic concept of capacity utilisation. For some manufacturing industries the AWC can provide a reasonable proxy of capital utilisation, but even then the concepts are not equivalent. As Carol Corrado explains in a critical comment on Shapiro (1996):

Shapiro's results ... are not as general as he casts them. He argues that the workweek of capital is a 'genuine measure of capital services' and uses the term interchangeably with 'capital utilization' and 'shift work.' He may do this with little loss of generality for an industry that has an assembly line technology, like motor vehicles, but for many other major industry groups it is inappropriate. (Corrado in Shapiro 1996, p. 122)

Corrado and Mattey (1997) distinguish between three types of stylised technology used by manufacturing firms: pure assemblers (for example, automakers), flexibly operated workstation assemblers (for example, apparel) and continuous processors (for example, oil refinery). It is the pure assemblers that tend to vary the workperiod as a key margin for adjusting output levels in the short run. For workstation assemblers the better proxy of capital utilisation is the number of workers and, for continuous processors, it is inputs of materials and energy. Even within manufacturing industries it cannot be generalised that: (i) varying the number of shifts is the main method for adjusting production levels in response to short-run rhythmic variations in demand; and (ii) there is long-run variability in the normal shift system.

Shapiro $(1986 ; 1996)$ is a long-standing advocate of the view that AWC measures can provide a better empirical guide to rates of capital utilisation. ${ }^{5}$ Gorodnichenko and

5. Note that measures of the AWC cannot capture changes in the speed of machinery operation. 
Shapiro (2011, p. 5) offer that: 'Capital utilization, $K U$, can be defined as multiplying the physical stock of capital, $K$, that yields a measure of capital services ... . A leading contender is to measure $K U$ as plant hours'. Thus:

$$
\begin{gathered}
K^{s}=\mu \bar{v} K \\
\mu=K^{s} / \bar{v} K,
\end{gathered}
$$

where $K^{s}$ is the flow of capital services, $\mu$ is the rate of capital utilisation, $v$ is the speed of machinery operation (and with the overbar used for an exogenous constant), and $K$ is the stock of physical capital. The authors follow Shapiro (1986) in modelling the work-period as follows:

$$
S=\left[H\left(L_{1}-L_{2}\right)+80\left(L_{2}-L_{3}\right)+120 L_{3}\right] / L_{1},
$$

where $S$ is the AWC, $L_{i}$ is the number of workers in the $i$ th shift, and $H$ is the average workweek of a worker (which is assumed to be 40 hours). The length of shifts and number of workers in each shift are assumed equal. The AWC is 40 hours with one shift, 80 hours with two shifts and 120 hours with three shifts. With these assumptions, then, capital utilisation and the AWC will coincide (so that $\mu=S$ ). In practice firms have additional adjustment margins such as through overtime hours and the number of workers on shifts. Nikiforos (2016, p. 439) decides to 'not make a distinction' between capacity utilisation and capital utilisation. Such a distinction would assist in understanding his position (and is also made in the AWC literature). ${ }^{6}$ Here we will relay the conventional definition of capacity utilisation:

$$
u=Y / Y_{f c},
$$

where $u$ is the rate of capacity utilisation, $Y$ is actual output, and $Y_{f c}$ is full-capacity output. Full-capacity output is the level that would be produced at 'full production'. It corresponds to the economic concept of potential output. A realistically achievable output level that differs from the engineering maximum level that could be produced if the factory was run continuously at full speed. The normal rate of capacity utilisation $u_{n}$ is the ratio of normal output $Y_{n}$ to full-capacity output:

$$
u_{n}=Y_{n} / Y_{f c} .
$$

Normal output is the level that would be produced while the firm still retains a degree of desired excess capacity (to adjust output to rhythmic variations in demand and deter new entrants). Curiously, though Nikiforos $(2013 ; 2016 ; 2018)$ argues that capacity utilisation should be redefined as the AWC, the argument is not formalised. The AWC concept of maximum output is much closer to the engineering concept than to the economic concept of full production / potential output. When relaying the NeoKaleckian model Nikiforos (2016, p. 440) uses the notation: ' $Y$ and $\bar{Y}$ is output and

6. “Capacity utilization" ... is a measure of actual output relative to potential, not a measure of capital utilization' (Shapiro 1986, p. 3). Beaulieu and Mattey (1998) are also clear that capacity utilisation and capital utilisation should not be used interchangeably: the two are distinct concepts. 
potential output $\ldots u=Y / \bar{Y}$ is capacity utilisation'. That there are no subsequent changes to the formal definition of $u$ is awkward. The macro model uses the same concept of capacity utilisation as the Fed. But the claims of the new approach require that the denominator of capacity utilisation cannot be potential output.

\section{MICRO-LEVEL ENDOGENEITY IN THE 'NORMAL UTILISATION RATE'}

Nikiforos's (2013) micro model has some similarities to that of Kurz (1986). One difference is that the former focuses on how decreasing returns to economies of scale may prompt a structural transformation in the operations of a representative firm. ${ }^{7}$ As Nikiforos (2013, p. 516) explains his position, 'the firm will tend to utilize its capital more - adopt a double shift system - as the demand for its output grows, if the rate of the returns to scale decreases'. Fixed capital will be utilised more in two senses:

(i) the time it is used each week; and (ii) in relation to the flow of output.

Girardi and Pariboni (2019) advance several criticisms of the restrictive micro setting: for example, it is inconsistent that only firms on the single-shift system enjoy increasing returns to scale (but at a diminishing rate). The authors are also unconvinced that the micro model provides support for the adjustment mechanism in the macro model. In the micro model Girardi and Pariboni (2019, p. 348) offer that ' $K^{i}$ is the amount of "capital services" $\ldots$ in the i-shift system' (emphasis in the original). But $K^{i}$ could be the capital stock. Nikiforos $(2013$, p. 523) is not clear when he states that the 'instantaneous rate of services of capital varies proportionally to the capital stock in place, $S=v K$, where $v$ is a constant [for the speed of operation] ... we can normalize $v=1$, so $S=K$ '. The AWC is usually presented as a determinant of capital services (Shapiro 1986; 1996; Mattey and Strongin 1997; Gorodnichenko and Shapiro 2011). A point stressed in the AWC literature is that $K^{s}$ varies in proportion to $K$ due to changes in the AWC (and $v$ ): 'much empirical work remains dependent on the counterfactual assumption of a proportional relation between capital stocks and capital service flows' (Beaulieu and Mattey 1998, p. 199).

Plant managers are instructed in the Survey of Plant Capacity (SPC) - which the Fed draws on when constructing its indexes of capacity utilisation - to estimate full-capacity output in reference to normal conditions and a realistic work schedule (rather than the engineering maximum). Some firms have no leeway to change the shift system in the short run or long run (for example, continuous processors). Other firms may vary the work-period through overtime hours or the number of shifts. We will suppose that the normal rate of capital utilisation, $\mu_{n}$, is when the plant is operating on its normal shift system with no overtime hours. The two rates of capital utilisation are higher in the double-shift system:

$$
\begin{aligned}
& \mu^{2}=2 \mu^{1} \\
& \mu_{n}^{2}=2 \mu_{n}^{1} .
\end{aligned}
$$

7. An emphasis is placed on the structural transformation from adopting a new normal shift system because this is what is implied for a firm that no longer requires approximately half of its fixed capital, or double the amount. 
Equation (8) states that the double-shift system has half the capital stock $K^{i}$ relative the single-shift system. ${ }^{8}$ Capital services are the same in each shift system despite the difference in stocks of physical capital due to the different rates of capital utilisation (equation (9)).

$$
\begin{gathered}
K^{2}=K^{1} / 2 \\
K^{s 2}=2 \mu^{1} \bar{v} K^{1} / 2=K^{s 1}
\end{gathered}
$$

Equations (10), (11) and (12) record respectively that actual output $Y^{i}$, normal output $Y_{n}^{i}$ and full-capacity output $Y_{f c}^{i}$ are the same in both shift systems. For a firm adopting a double-shift system the positive effect on the level of its potential output $Y_{f c}^{2}$ from the increase in its normal shift system (and thereby $\mu_{n}^{2}$ ) is offset by the diminishment in its fixed-capital requirements. ${ }^{9}$

$$
\begin{gathered}
Y^{2}=Y^{1} \\
Y_{n}^{2}=Y_{n}^{1} \\
Y_{f c}^{2}=Y_{f c}^{1}
\end{gathered}
$$

By definition $u^{i}=Y^{i} / Y_{f c}^{i}$ and $u_{n}^{i}=Y_{n}^{i} / Y_{f c}^{i}$ are the same in both shift systems:

$$
\begin{aligned}
& u^{2}=u^{1} \\
& u_{n}^{2}=u_{n}^{1} .
\end{aligned}
$$

Capacity utilisation and capital utilisation do not coincide. Alternatively, using the subscript $m$ for the maximum level of output that could be produced if the plant were operated for the maximum amount of time during a week, then $\widetilde{u}^{i}=Y^{i} / Y_{m}^{i}$ and $\widetilde{u}_{n}^{i}=Y_{n}^{i} / Y_{m}^{i}$. With these definitions:

$$
\begin{aligned}
& \widetilde{u}^{2}=Y^{1} /\left(Y_{m}^{1} / 2\right)=2 \widetilde{u}^{1} \\
& \widetilde{u}_{n}^{2}=Y_{n}^{1} /\left(Y_{m}^{1} / 2\right)=2 \widetilde{u}_{n}^{1},
\end{aligned}
$$

where the tilde denotes the AWC concept of capacity utilisation. Maximum output $Y_{m}$ is lower in the double-shift system because of the comparative diminishment in fixed-capital requirements. Nikiforos's (2016) decision to formalise $u$ in view

8. We are considering here Nikiforos's $(2013 ; 2016)$ case with a so-called single technique of production. Note that even this case is a misnomer since 'the single-shift system displays a higher K/L ratio' (Girardi and Pariboni 2019, p. 351).

9. Nikiforos $(2013 ; 2016)$ does not contemplate how the firms that switch to a double-shift system will dispose of their excess fixed-capital requirements. If those firms, which require around half the capital stock to produce the same output level vis-à-vis the single-shift system, were to sell their excess capital stock in secondhand markets there could be a glut (and a recession for producers of capital goods). 
of potential output is confused. His claims seem to be that the trend in the conventionally defined normal rate of capacity utilisation is exogenous and static because the denominator in $u_{n}=Y_{n} / Y_{f c}$ is affected by the choice of normal shift system; and vice versa for the denominator in $\widetilde{u}_{n}=Y_{n} / Y_{m}$. From an empirical perspective the new approach predicts divergent trends in $u$ and $\widetilde{u}$ and that only $\widetilde{u}$ has a systematic positive relation with effective demand pressures. ${ }^{10}$ Additional assumptions include that: (i) the AWC is a good theoretical and empirical proxy for $\mu$; (ii) variability in the normal shift system can be generalised across all industries; and (iii) long-run trends in the normal shift system can be attributed in some fundamental way to effective demand pressures.

As a preliminary to looking at the empirics it is appropriate to first consider in more detail the factors that influence the choice of the normal shift system. My reading of Nikiforos's $(2013 ; 2016)$ micro and macro models is that the incentives for firms to adopt a double-shift system are as follows:

1. a decrease in the aggregate wage cost relative to total production costs;

2. a decrease in the second shift wage premium;

3. an increase in the unit cost of fixed capital (in the form of machines);

4. an increase in the capital-intensiveness of production techniques;

5. a decrease in economies of scale; and

6. an increase in the expected permanent level of demand for the product of a representative firm in the micro model / an increase in the actual growth rate of aggregate demand above the expected growth rate of aggregate demand in the macro model.

Point 1 is relevant to the US manufacturing sector since the $1980 \mathrm{~s} .{ }^{11}$ With the decline in union representation, and growing casualisation of the workforce, a lower wage premium for working outside normal hours seems likely. Point 3 receives no commentary. Point 4 may be important (for example, the trend to automation). Point 5 is unverifiable yet critical to the new approach. Point 6 is the leap from static micro-level to dynamic macro-level. As economies of scale evolve with technical conditions, it is difficult to imagine that a similar trade-off between effective demand pressures and the extent to which there are decreasing returns from economies of scale would get continuously replicated over time for the average-sized firm. We will add some additional considerations:

7. a decrease in the depreciation rate from wear and tear;

8. an increase in the depreciation rate from technological obsolescence;

9. an increase in depreciation allowances;

10. an increase in the unit price of structures (excluding land);

11. an increase in the unit price of land; and

12. an increase in the energy price discount for operating outside of peak demand.

10. On the old approach, see Lavoie (1995), Dutt (1997), Dallery and van Treeck (2011) and Hein et al. (2012).

11. According to the US Bureau of Economic Analysis's industry data, the wage share (that is, employee compensation to gross value added) in private industries declined by a modest 2.6 percentage points from 52.4 per cent in 1987 to 49.8 per cent in 2017 , whereas in manufacturing industries it declined by an unprecedented 17.3 percentage points over the same period from 63.7 per cent to 46.4 per cent. 
Nikiforos $(2013$; 2016) ignores capital depreciation. Point 8 is relevant, although the extent to which the higher depreciation allowances since the 1960s reflect a shortening of capital service lives or a quasi-tax break for businesses can be debated. Point 9 could incentivise point 4 and thereby foster an increase in the AWC. Whatever the trend for points 10 and 11, these provide other incentives to add a shift. Finally, as to point 12 , even households are nowadays offered a price discount for using energy outside of peak demand. There is no a priori reason to follow the new approach and give preference to point 6 as the exclusive explanation of trends in the AWC for the US manufacturing sector.

\section{SOME EMPIRICAL CONSIDERATIONS}

Literature on the AWC has documented trends for US manufacturing industries. Foss (1984) used as a proxy for the AWC the percentage of workers employed in second and third shifts. He could only estimate intermittent observations from 1929 to 1978/1979. Foss (1995) was later able to construct an annual data set for the period 1976-1988. His finding of an accelerated trend for 1976-1988 is difficult to explain in terms of upward effective demand pressures. Heterodox economists date the start of the Neoliberal era to the late 1970s. Economic growth disappointed relative to the Golden Age. ${ }^{12}$

Foss (1981a; 1981b) argued that there were two main factors behind the upward trend in the AWC from 1929 to 1976: (i) an increase in firms within certain industries running multiple shifts; and (ii) an increase in the share of continuous processors in the manufacturing sector's output (from around 16-20 per cent in 1929 to 28 per cent in 1976). So the upward trend in the AWC is partly explained by changes in industry composition: a story about changes in relative demand for the products of certain industries. ${ }^{13}$ If aggregate demand is to matter for the normal shift system then the prerequisite is industries where variability in the normal shift system is a relevant consideration. Recalling Corrado and Mattey's (1997) three stylised technologies, we can rule out continuous processors, and at least some proportion of the workstation assemblers that are known to nearly always operate on a single-shift system (for example, apparel and leather). The representative firm of the new approach is not so representative.

Table 1 presents various estimates of the AWC in the US manufacturing sector. The estimates of Taubman and Gottschalk (1971), Shapiro (1986), Orr (1989) and Mayshar and Solon (1993) are based on data from the Area Wage Survey (AWS). Nikiforos (2016) presents the data of those authors except for Mayshar and Solon (1993). In all cases he impresses on the reader an upward trend. Table 1 also shows the estimates of Beaulieu and Mattey (1998) and Gorodnichenko and Shapiro (2011) derived from SPC data (and the Annual Survey/Census of Manufactures for assigning plants to industries). The two SPC data sets are not directly comparable as

12. US manufacturing firms expanded their fixed capital in real terms at an annualised rate during the 1980s of less than half that during 1948-1979. The decision to increase shifts as an alternative to investing more in fixed capital contributed to the slowdown in effective demand (as capital expenditures are a component of effective demand).

13. For example, the share in manufacturing output of the continuous processing industry chemicals increased from 5.9 per cent in 1947 to 17.7 per cent in 2017. Aggregate trends in the AWC could also be affected by an increase in the degree of oligopoly amongst pure and workstation assemblers (as larger-sized firms are more likely to run multiple shifts). 
Table 1 The average workweek of capital in US manufacturing firms

\begin{tabular}{lcc}
\hline & Mean & Linear trend \\
\hline Area Wage Survey 1952-1982: & 51.3 & \\
$\quad$ Taubman and Gottschalk (1971) & 54.9 & 0.14 \\
Shapiro (1986) & 53.8 & 0.03 \\
Orr (1989) & 54.0 & 0.14 \\
Mayshar and Solon (1993) & 89.9 & 0.11 \\
Survey of Plant Capacity 1974-1992: Beaulieu and Mattey (1998) & \\
No weights & 106.2 & 0.43 \\
Fixed employment & 63.3 & 0.28 \\
Survey of Plant Capacity 1974-1997: Gorodnichenko and Shapiro (2011) & \\
Sampling weights only & 100.0 & 0.72 \\
+ Output (value of shipments) & 109.1 & 0.72 \\
+ Capital stock (historical cost) & 89.0 & 0.62 \\
+ Employees & & 0.69 \\
\hline
\end{tabular}

Gorodnichenko and Shapiro adjust for influential observations. Of interest is that the SPC data sets report a higher level and trend for the AWC in hours per week than the AWS data sets.

Nikiforos (2016) seeks to provide empirical support using data for all US firms. One would think that AWC data are better suited to verifying claims on shiftwork than a proxy. The issue of whether a variable normal shift system is a relevant consideration to non-manufacturing firms is skipped past. ${ }^{14}$ Data are presented to confirm the claim that when there are decreasing returns to economies of scale "entrepreneurs will have the incentive - under the cost-minimising principle - to meet the increasing demand for their firm's product not by expanding their plants, but rather by utilising them more, i.e. by readjusting their desired rate of utilisation upwards' (ibid., p. 453, emphasis in the original). 'Firm's product' should be output and 'plants' should be some measure of the capital stock. This is not the path taken. Empirical support is claimed on the basis of data for all US firms over 1990-2010 which shows the 'increase in aggregate demand is accommodated to a large extent through an increase in the number of the firms' (ibid.). Yet, unless new firms require no fixed capital to produce output, an increase in the number of firms implies an increase in the quantity of fixed capital. Additional data are presented.

We proxy the size of the firms with the ratio of total employees over number of firms ... and over number of establishments .... . We proxy the expected growth rate by applying the ... [Hodrick-Prescott] filter to the actual growth rate series .... The two subfigures and related regressions confirm that when growth rates are higher than expected there is an increase in the average size of the firm (and vice versa). (Ibid., pp. 454-455)

14. Comparing, say, a hospital to a primary school, there is diversity in the number of normal shifts, yet not much scope for change. And in a hospital some of the specialist areas will only be fully staffed during day shifts (and the same goes for administration staff). Transportation industries respond to demand fluctuations, not by changing the number of shifts (for example, whether drivers work the midnight-to-dawn shift), but by altering the number of workers on each shift. Certainly, while there are exceptions, for many service industries some idleness in fixed capital is obligated by the verity that the vast majority of potential customers are asleep between $11 \mathrm{pm}$ and $7 \mathrm{am}$. 
Girardi and Pariboni (2019) object to the robustness of the econometric results and methods. Whether a Hodrick-Prescott filter can be used to proxy firms' expected growth rate is another question. ${ }^{15}$ It is not clear what the ratio of employees per firm or establishment can establish. A first point is that observations over a short time horizon will capture cyclical rather than secular trends. A second point is that the number of firms (or establishments) cannot provide a proxy for 'plants' / fixed capital: employees and fixed capital can increase in tandem. A third point is that AWC data sets would seem better suited to verifying claims on shiftwork (and the AWC).

Figure 1a presents the Mayshar and Solon (1993) AWS data set for the period 1951-1990. ${ }^{16}$ An upward trend is apparent even though the final year 1990 is a recession (and also unrepresentative in terms of the surveyed cities). ${ }^{17}$ Figure $1 \mathrm{~b}$ presents the Gorodnichenko and Shapiro (2011) SPC data set weighted by sampling weights and the number of employees for the periods 1974-1997 and 1999-2004. Data for 1998 was miscoded. The picture that emerges is that the upward trend in the AWC continued throughout the 1990s and then moderated with the 2001 recession; nonetheless, the AWC was at a higher level in the early 2000s vis-à-vis a comparable point during the previous cycle in the early 1990s. This brings us to a question. Suppose that the AWC does equal the rate of capital utilisation and the rate of capacity utilisation: does it make sense for the 'utilisation rate' to be substantially higher in the early 2000s than, say, in the mid 1960s when US output growth was substantially faster? It would be contrary to the premise in the Neo-Kaleckian model of endogeneity in the normal utilisation rate.

Figure 1c presents filtered trends for the Mayshar and Solon (1993) AWS data set and the growth rate of manufacturing output. Output is the Fed's series for industrial production. The parameter for the Hodrick-Prescott (HP) filter is the recommended value for annual data of 100. As HP-filtered data are sensitive to endpoints we construct a trend over 1951-1990 and then remove four years from each side. What stands out is that the AWC and output growth are negatively correlated from the mid 1960s until the late 1970s. Figure 1d repeats the process using instead the Fed's index of capacity utilisation for the manufacturing sector. There is a closer relation between the filtered trends in $u$ and output growth. Nikiforos (2016) presents annual data smoothed by an HP-filtered parameter of 1600 (as is recommended for quarterly data). A larger parameter accentuates the negative relation between output growth and the AWC (Figure 1e) and vice versa for $u$ (Figure 1f). Over 1951-1990 the simple correlation coefficient for output growth and the AWC is 0.28 which compares to 0.60 for output growth and the Fed's $u$. For the filtered trend over 1955-1986 the correlation coefficient between output growth and the AWC is -0.50 and -0.96 with respective smoothing parameters of 100 and 1600. And for the Fed's $u$ : 0.89 and 1.00.

15. There may also be a simple reason why Nikiforos's (2016, p. 455) results do not hold when 'we use the actual growth rate'. A first margin of adjustment is overtime hours (and the hours worked by casual workers). Firms that produce goods also initially respond to demand fluctuations through changes in inventory stocks.

16. Mayshar and Solon (1993, p. 224) exclude cities which appear only once in the AWS 'to generate a consistent national annual time series on shift work in manufacturing'. For Shapiro (1996, p. 87), '[t]heir work provides the most up-to-date analysis of the AWS data'. We follow Shapiro in calculating the AWC from AWS data and the US Bureau of Labor Statistics' data on the average weekly hours of production and non-supervisory employees in manufacturing.

17. In the Mayshar and Solon (1993) data set the average number of cities surveyed is 30 . The lowest is 12 in 1990. 

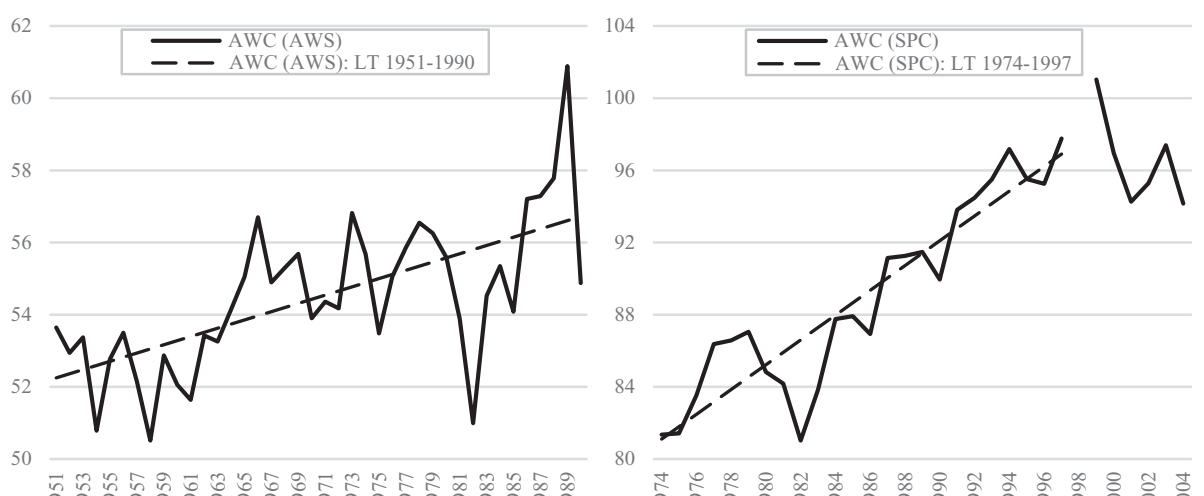

$\left(a^{\mathrm{a}}\right.$

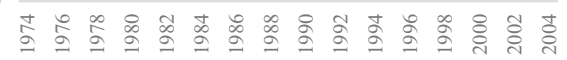

$(b)^{\mathrm{a}}$
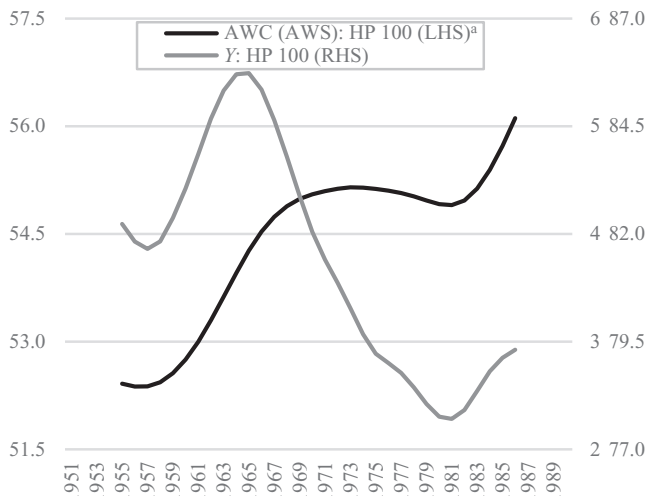

$(c)^{b}$
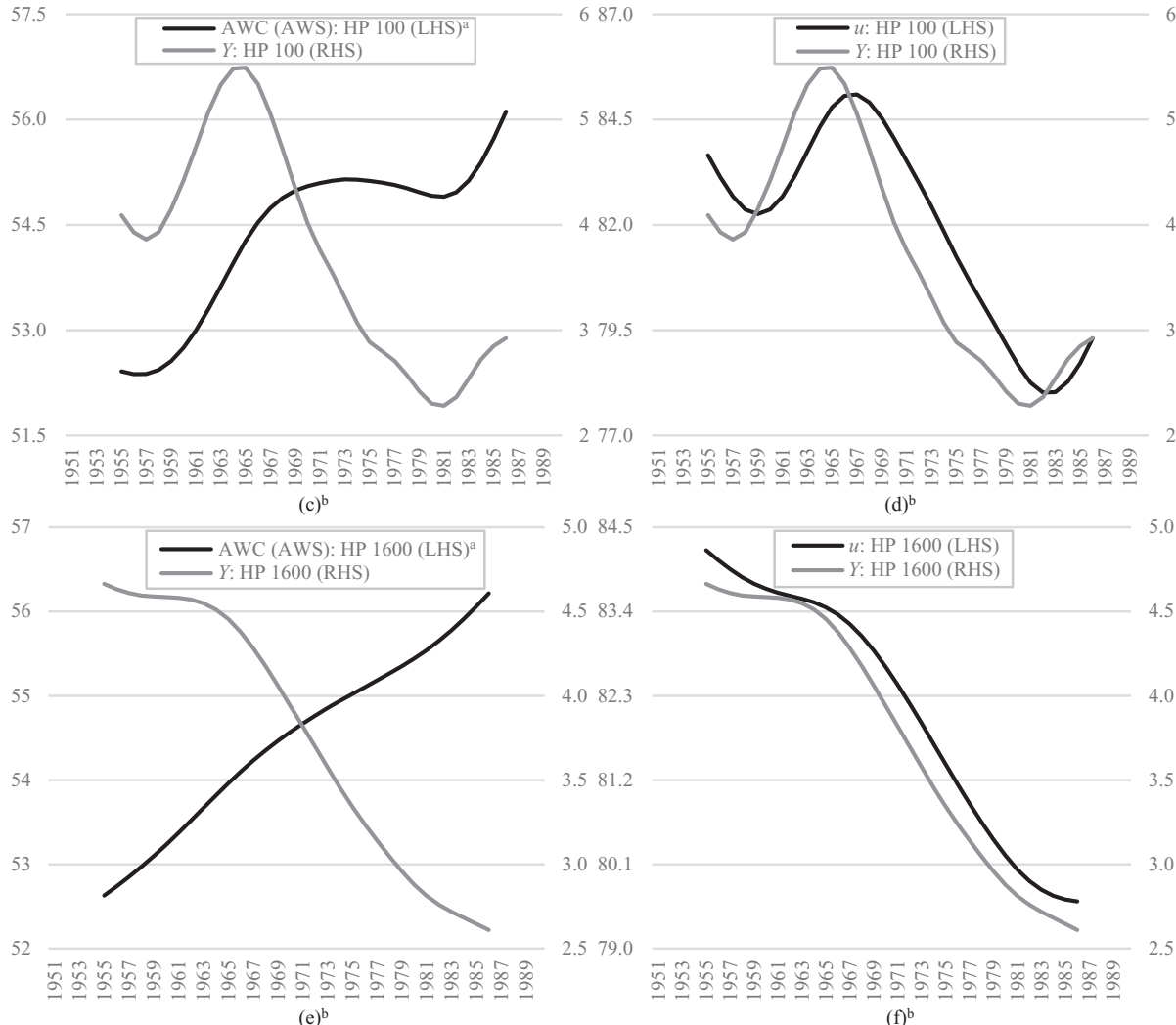

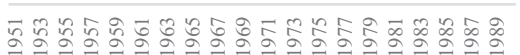

(d) ${ }^{\mathrm{b}}$

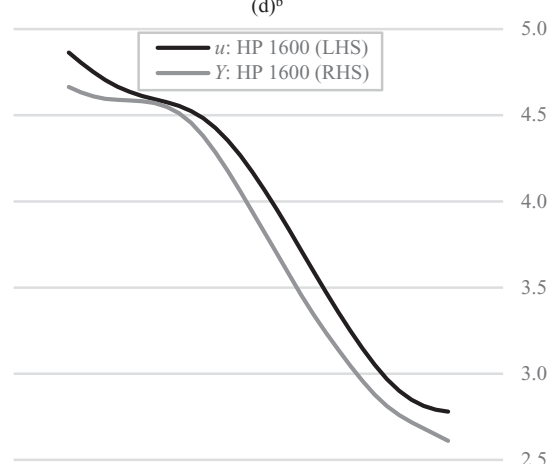

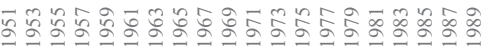

$(\mathrm{e})^{\mathrm{b}}$

$(\mathrm{f})^{\mathrm{b}}$

Notes: a. Hours per week. b. HP trend is calculated over 1951-1990.

Sources: Gorodnichenko and Shapiro (2011); Mayshar and Solon (1993); St. Louis Federal Reserve, FRED, AWHMAN, CUMFNS and IPMANSICN.

Figure 1 Annual trends in the average workweek of capital in the US manufacturing sector 


\section{TRENDS IN THE FED'S INDEXES OF CAPACITY UTILISATION}

Trends in utilisation rates have featured in debates between Neo-Kaleckians and critics. The possibility that HP-filtered data could approximate $u$ is suggested by Skott (2012, p. 132) and Nikiforos (2016, p. 445). Many heterodox economists may be disinclined to follow suit. As the normal utilisation rate is an unobservable magnitude then attempts to proxy it may be misleading. ${ }^{18}$ In the absence of a reliable empirical measure of $u_{n}$ the issue becomes a theoretical one. ${ }^{19}$ Is there any reason to suppose that the trend average utilisation rate will coincide with the normal utilisation rate? Unless one is willing to contemplate the (absurd) possibility that firms possess perfect foresight regarding the future path of aggregate demand, and are therefore able to precisely adjust capacity in such a way so to ensure that the capital stock will be utilised at the normal or desired planned degree, then the trend average utilisation rate and the normal utilisation rate should only ever coincide by fluke (Smith 2012).

With the above caveats we proceed to empirical findings based on the assumption that the normal utilisation rate can be approximated by long-run time averages. Skott and Zipperer (2012: 294) claim that the long-run trend for capacity utilisation in US manufacturing firms 'seems roughly flat'. Skott and Zipperer (2011) present quarterly HP-filtered trends and use the parameter of 129600 (that is recommended for monthly data) for the long-run trend. Nikiforos (2016) does not adjust for endpoints and excludes the years of low rates after 2007. He observes on annual data for the period 1948-2007:

It is hard to see how these data support the claim of an endogenous utilisation rate. From the fitted lines it becomes obvious that the rate of capacity utilisation tends to gravitate around a constant rate over a prolonged period of time, approximately $83 \%$ in the period $1948-80$ and approximately $79 \%$ in the period 1980-2007. This change can be attributed to a change of the structural characteristics behind the desired rate of utilisation. (Ibid., pp. 444-445)

Adding three years changes the linear trend from 0.00 over 1980-2007 to -0.15 over 1980-2010. The period 1980-2007 seems to be arbitrarily selected: the starting point is a double-dip recession and the endpoint is a cyclical peak. The demarcation periods 1948-1980 and 1980-2007 coincide with the start of the Neoliberal era. Is it possible that a slowdown in aggregate demand could explain the 4-percentage-point fall in the Fed's $u$ ? Not so for Nikiforos $(2012 ; 2016)$, who points to a paper by Fed researchers Morin and Stevens (2004) to support his claim that the 4-percentage-point decline in the linear trend between the two periods is due to a structural break in the SPC survey. Nikiforos (2012, p. 9) offers on the hypothesised change in the structural characteristics of $u_{n}$ between 1948-1980 and 1980-2007:

For example, Spence (1977) would argue that this shift is the result of an increase in the concentration in the market and as a result the firms need to lower their utilization rate to deter the entry of the competitors. However, we do not have to go that far. Morin and Stevens (2004, p. 9), in a paper describing the construction of the FRB capacity utilization index, argue that a big part - if not the whole - of this decrease is due to changes in the definition of capacity in the questionnaires of the surveys which are used to construct the index. These changes led to a

18. The HP filter constructs its trend by attaching weight to past and future data. It is highly doubtful that the normal utilisation rate could be inferred from a filter which uses future values that are unknowable to firms.

19. I thank an anonymous referee for drawing my attention to this point. 
'discrete shift' of the index around '4 percentage points'. It is probably no coincidence that this is the difference between the two horizontal fitted lines.

The case for a structural break seems compelling. Nikiforos $(2016$, p. 445) is less emphatic but still claims that the difference in linear trends between 1948-1980 and 1980-2007 can be explained by 'changes in the sources of the data and the way the series are constructed'. He quotes a short passage from Morin and Stevens (2004, pp. 8-9) that we will instead quote in full:

The SPC has implemented three significant changes since 1974. First, in 1982 respondents were requested to complete the survey form even if the plant was idle (but not permanently closed) during the fourth quarter. Presumably, before 1982, the SPC undercounted idled plants, and, consequently, reported industry-level utilization rates that were higher in downturns than would otherwise have been the case (although this has been difficult to detect statistically).

Nikiforos (2016, p. 445) does not provide the context for assessing the potential significance of one of the changes to the SPC survey by quoting only the final sentence (and even then truncating the first word 'presumably'). What proportion of firms would fit the following criterion: idled but not permanently closed in the fourth quarter? Mattey and Strongin $(1997$, p. 8) report from SPC data that the proportion of manufacturing firms operating for less than eight weeks in the fourth quarter averaged 0.3 per cent over 1979-1988. While the period includes three years before idled but not permanently closed firms were not requested to complete surveys, and seven years when they were, it would seem safe to infer that the proportion of idled but not permanently closed firms is close to or less than the proportion of firms operating for less than eight weeks. As so it is unsurprising that the 1982 change to the SPC survey is 'difficult to detect statistically' (Morin and Stevens 2004, p. 9).

The second significant change to the SPC survey identified by Morin and Stevens is a change in the definition of capacity output: "before the 1989-1990 survey, plant managers were asked about their "preferred level of operation" and "practical capacity"; now the survey asks for the level of "full production" and "national emergency production"" (ibid.). For the Fed researchers, "the definitions of "preferred level of operation" and "full production" appear close enough that they are treated as a single time series without any ad hoc adjustments' (ibid.). A footnote reference is given to Doyle (2000), who examines these issues in detail and states her findings in the abstract: "the preponderance of evidence in this study suggests that "preferred" utilization is consistent with "full" utilization and, therefore, supports the underlying Federal Reserve methodology for estimating capacity utilization'. Morin and Stevens (2004) do not argue that 'the change in the questionnaires of the Census from the one definition to the other [that is, from preferred capacity to full production] led to a small discrete change in the reported utilization (around four percentage points)' (Nikiforos 2012 , p. 2). But even if the authors did make that argument, which they do not, the structural break would be 1989 (not 1980).

The third change to the SPC survey identified by Morin and Stevens $(2004$, p. 9) is as follows:

In surveys before the 1995-1996 SPC, the respondent was instructed to determine capacity hours and shifts by using the maximum level attained in the last five years; since then, the respondent is allowed to assume extra shifts at capacity: 'If full production requires additional shifts or hours of operation, then appropriate downtime should be considered in the estimate'. (Emphasis added by Morin and Stevens) 
The authors then conjecture that 'one would expect that utilization rates should have exhibit $[s i c]$ a discrete downward shift in 1995. This shift is observed in the data ... about 4 percentage points' (ibid.). If so, the structural break would be 1995 (not 1980). But Morin and Stevens are mistaken. The five-year moving maximum shift instructions did not apply to SPC surveys before 1995-1996 per se but only to the biannual surveys conducted over 1989-1990 and 1993-1994. The authors should have been aware of the limited time when the different instructions were applied, as is mentioned by Doyle (2000, p. 10), who also considers that the effect was likely to be minimal: "constraining the workweek to be within the range experienced by the plant over the previous five years may not be a binding constraint in the early nineties, given that 1988 was a peak in Federal Reserve estimates of manufacturing utilization'.

Figure 2 presents quarterly trends in US manufacturing capacity utilisation over 1948-2017. Figure 2a shows that variation in the HP-filtered trend is greater when the normal parameter is used instead of that for monthly data. Figure $2 \mathrm{~b}$ enables a comparison between the mean and linear trends. The linear trend over 1948-2017 is -0.14 at an annualised rate and increases to -0.22 over $1965-2017$. Figure $2 \mathrm{~b}$ also presents HP-filtered trends - with the arbitrary large parameter of 129600 - for $u$ and the growth rate of US non-financial corporate real gross value added $(Y-N C)$. If the Fed's index was constructed to be stationary then the linear and HP-filtered trends should resemble the mean (which is 80 per cent over 1948-2017). And, further, that the positive relation between $u$ and $Y-N C$ in Figure $2 \mathrm{~b}$ should not exist. The data seems to lend some support to the old approach.

It is worth mentioning that the decades-long decline in US manufacturing capacity utilisation is not due to changes in industry weighting for value added (Pierce and Wisniewski 2018). Table 2 reports the mean, linear trend and HP-filtered range in $u$ for manufacturing industries where quarterly data is available from 1948. The HP trend is constructed over 1948-2017 while the range reported is that over 1952-2013. If HP-filtered data smoothed by an arbitrary large parameter can approximate $u_{n}$, then the band for the US manufacturing sector is 10 percentage points, although in some industries it is as high as 20-26 percentage points. When using the normal HP parameter for quarterly data the band is 15.7 percentage points (and for some industries as high as 31-35 percentage points).

Industry-level data for chain-type quantity index growth rates of gross value added are available on an annual basis from 1948. Figure 3 presents HP-filtered trends for capacity utilisation and the growth rate of real value added for US non-financial corporations, the manufacturing sector and the industries in Table $1 .{ }^{20}$ Data are adjusted for endpoints. The parameter is the recommended value for annual data. The picture that emerges is that trends in effective demand and capacity utilisation are positively related. An exception is petroleum and coal products during the $1970 \mathrm{~s}$ and $1980 \mathrm{~s}^{21}$

20. It might be preferable to use the total industry capacity utilisation index for non-financial corporations, but as the series only begins in 1967 we use the manufacturing index. Capacity utilisation for industries is its own series.

21. The industry petroleum and coal products has a high standard deviation for real output growth rates at 40.4 per cent over 1948-2017. The range in real output growth rates is large for annual data: 288 per cent in 1948 and -57.5 per cent in 1949. The standard deviation falls by half to 21.3 per cent over 1950-2017. Figures 3d and 4d construct the HP trend over 1950-2017. Note also that Figures $3 \mathrm{i}$ and $4 \mathrm{i}$ for the industry motor vehicles, bodies and trailers, and parts are adjusted for influential observations. The real value added of this industry declined by 6.6 per cent from 2007 to 2011 . Growth rates were -21.7 per cent in $2008,-54.6$ per cent 


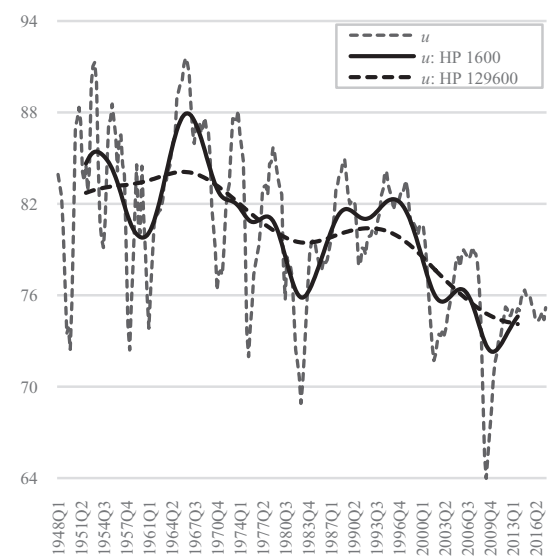

(a)

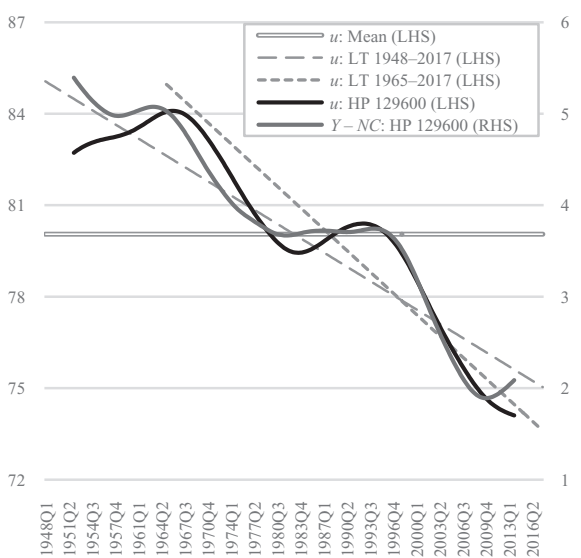

(b)

Note: The HP trend is constructed over 1948-2017.

Sources: St. Louis Federal Reserve, FRED, CUMFNS; US Bureau of Economic Analysis: GDP \& Personal Income, table 1.14 .

Figure 2 Quarterly trends in US manufacturing sector capacity utilisation, 1948-2017

Table 2 Quarterly trends in US manufacturing sector capacity utilisation by industry

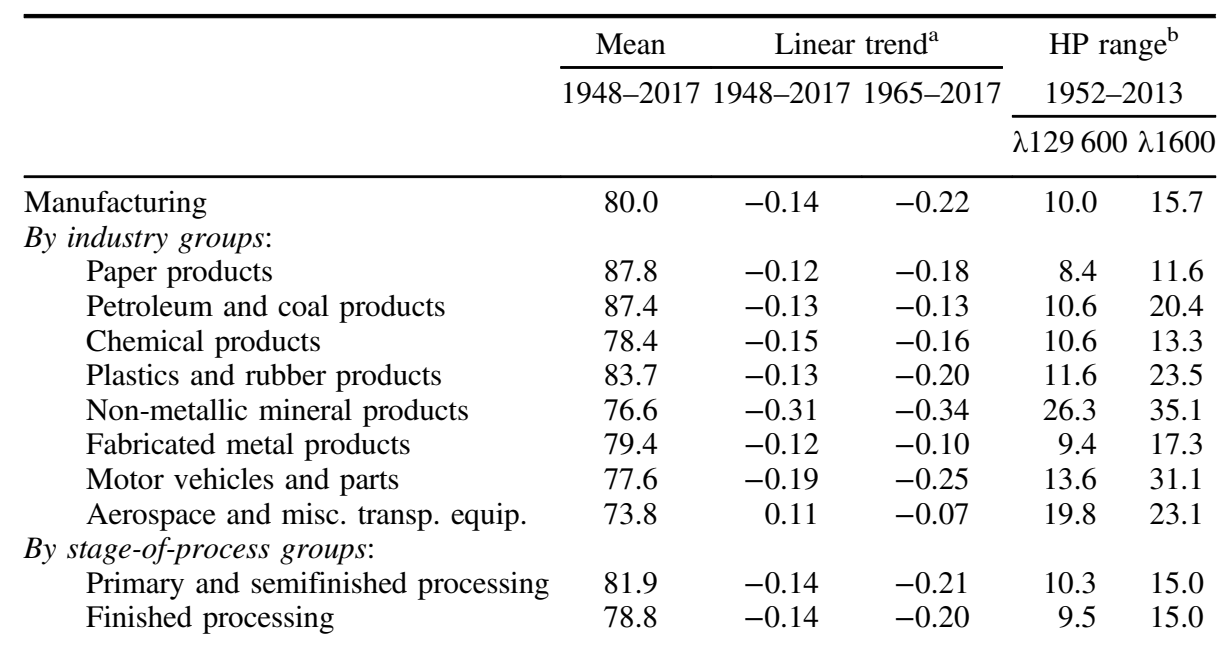

Notes: a. Annualised. b. Constructed over 1948-2017.

Source: St. Louis Federal Reserve, FRED, CUMFNS, CAPUTLB562A3CS, CAPUTLB5640CS, CAPUTLG322S, CAPUTLG324S, CAPUTLG325S, CAPUTLG326S, CAPUTLG327S, CAPUTLG332S, CAPUTLG3361T3S, CAPUTLG3364T9S.

in $2009,105.9$ per cent in 2010 and 27.8 per cent in 2011 . The high growth rate in 2010 distorts the HP-filtered trend. Data for real value added is adjusted by assuming a constant growth rate over 2008-2011 that achieves a cumulative 6.6 per cent decline from 2007 to 2011. 


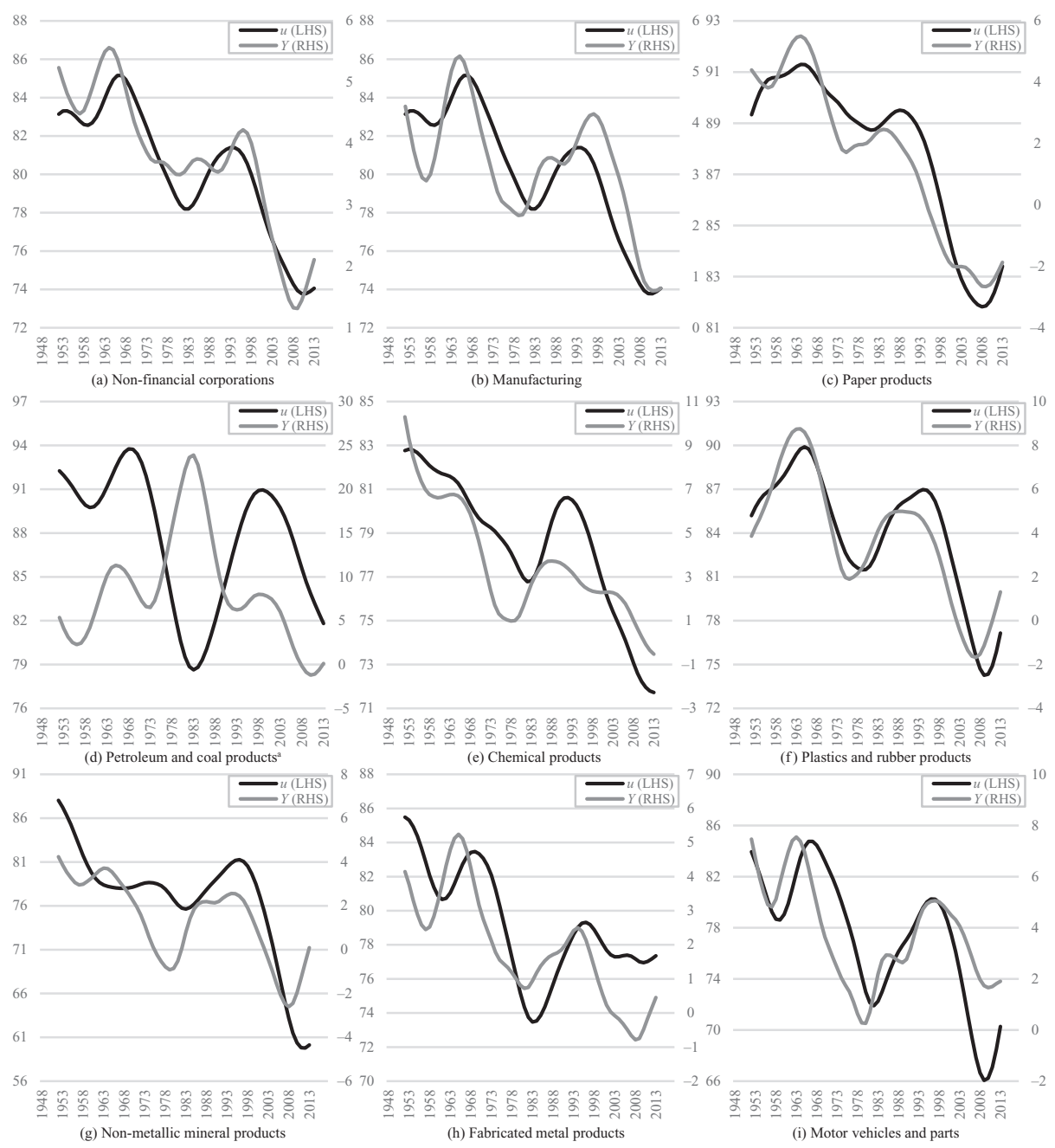

Notes: HP trend constructed over 1948-2017. a. HP trend constructed over 1950-2017.

Sources: St. Louis Federal Reserve, FRED, CUMFNS, CAPUTLB562A3CS, CAPUTLB5640CS, CAPUTLG322S, CAPUTLG324S, CAPUTLG325S, CAPUTLG326S, CAPUTLG327S, CAPUTLG332S, CAPUTLG3361T3S; US Bureau of Economic Analysis: GDP \& Personal Income, table 1.14; GDP-byIndustry, Value Added.

Figure 3 Annual trends in US manufacturing sector capacity utilisation and gross value added by industry (normal HP parameter of 100), 1952-2013

Figure 4 repeats the process with the arbitrary large parameter recommended for quarterly data. Here we get flatter versions of the panels in Figure 3. Table 3 reports the mean, linear trend and HP-filtered range in $u$ for industries where data is available from 1967. Data is again adjusted for endpoints by reporting the range over 1971-2013. The final two columns show the range over 1967-2013. For most industries the peak trend value in capacity utilisation would be in the mid 1960s; hence, the final two columns in Table 3 may be more comparable to Table 2 . 


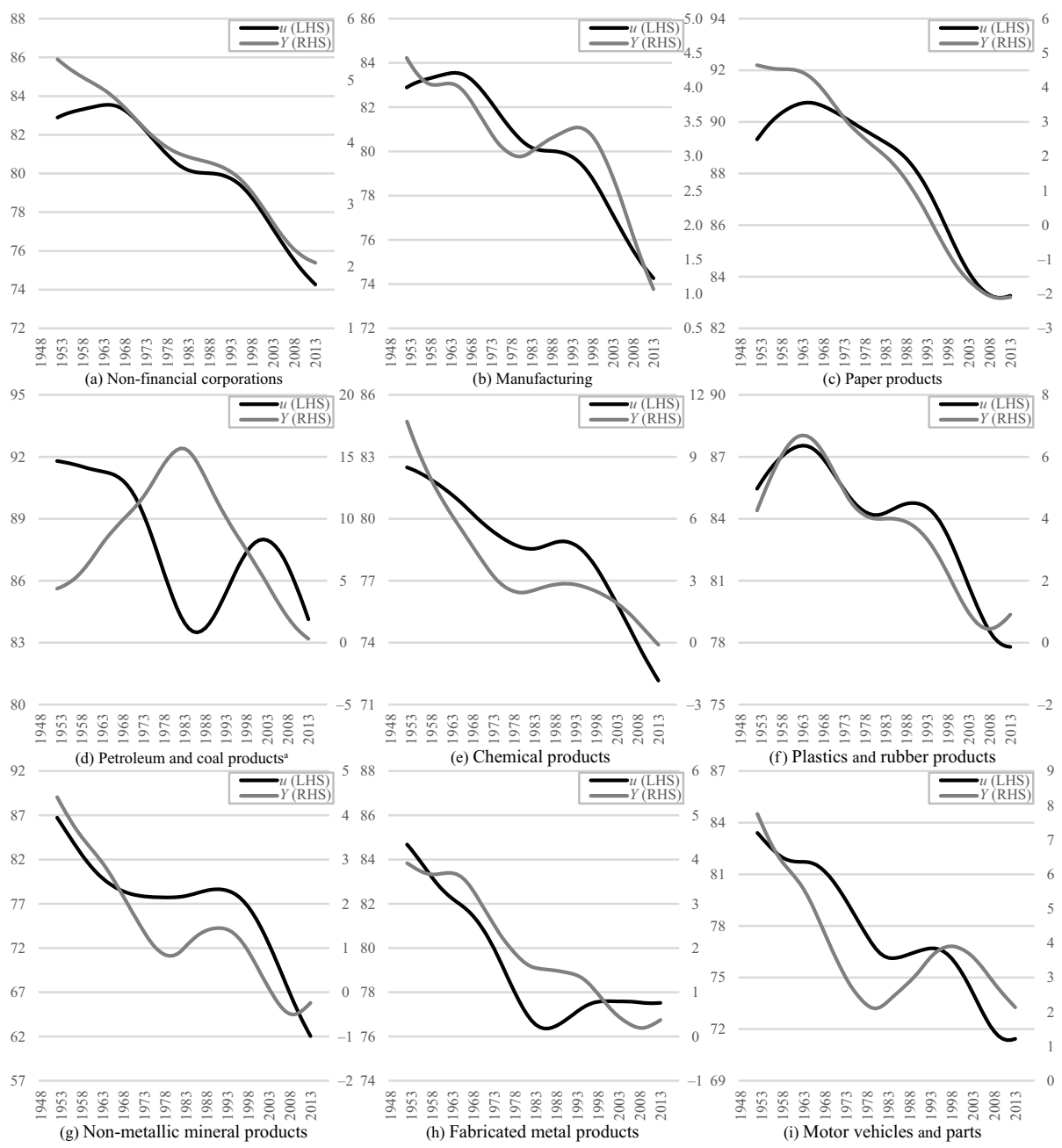

Notes: HP trend constructed over 1948-2017. a. HP trend constructed over 1950-2017.

Sources: St. Louis Federal Reserve, FRED, CUMFNS, CAPUTLB562A3CS, CAPUTLB5640CS, CAPUTLG322S, CAPUTLG324S, CAPUTLG325S, CAPUTLG326S, CAPUTLG327S, CAPUTLG332S, CAPUTLG3361T3S. US Bureau of Economic Analysis: GDP \& Personal Income, table 1.14; GDP-byIndustry, Value Added.

Figure 4 Annual trends in US manufacturing sector capacity utilisation and gross value added by industry (arbitrary large HP parameter of 1600), 1952-2013

To sum up: the empirical case for endogeneity in the normal rate of capacity utilisation would be unpersuasive if the general experience were, say, that of the mining industry. Exceptions do not make the rule. If we are to interpret HP-filtered data smoothed by an arbitrary large parameter as an approximation to $u_{n}$ then there is significantly greater endogeneity than recognised in the literature. And, further, that effective demand pressures influence $u_{n}$. Changes in the structural characteristics of $u_{n}$ may also be implicated in the downward trend. Other interpretations of the data are also possible. 
Table 3 Quarterly trends in US manufacturing sector capacity utilisation by industry, 1967-2017

\begin{tabular}{|c|c|c|c|c|c|c|}
\hline & \multicolumn{2}{|c|}{$1967-2017$} & \multicolumn{4}{|c|}{ HP range ${ }^{b}$} \\
\hline & \multirow[b]{2}{*}{ Mean } & \multirow[b]{2}{*}{ inear trend ${ }^{\mathrm{a}}$} & \multicolumn{2}{|c|}{$1971-2013$} & \multicolumn{2}{|c|}{$1967-2013$} \\
\hline & & & $\lambda 129600$ & $\lambda 1600$ & $\lambda 129600$ & $\lambda 1600$ \\
\hline Total industry index & 80.3 & -0.16 & 7.9 & 8.6 & 9.1 & 12.7 \\
\hline Manufacturing (SIC) & 78.8 & -0.19 & 9.1 & 10.1 & 10.4 & 14.1 \\
\hline Durable & 77.5 & -0.18 & 9.1 & 10.5 & 10.5 & 15.6 \\
\hline $\begin{array}{l}\text { Computers, communications } \\
\text { equip. and semiconductors }\end{array}$ & 78.1 & -0.18 & 8.0 & 14.8 & 10.3 & 19.9 \\
\hline Furniture and related products & 77.9 & -0.29 & 15.1 & 22.7 & 17.4 & 25.7 \\
\hline Machinery & 78.0 & -0.22 & 10.8 & 16.8 & 12.4 & 17.9 \\
\hline Primary metal & 78.7 & -0.19 & 12.4 & 22.7 & 15.2 & 22.7 \\
\hline Non-durable & 80.6 & -0.19 & 8.6 & 10.3 & 9.6 & 11.9 \\
\hline Food, beverage and tobacco & 81.0 & -0.16 & 6.8 & 7.3 & 7.4 & 8.0 \\
\hline Leather and allied products & 72.3 & -0.59 & 25.6 & 23.4 & 28.4 & 32.2 \\
\hline Electric and gas utilities & 86.4 & -0.20 & 12.7 & 15.2 & 16.2 & 18.1 \\
\hline Mining & 86.9 & -0.04 & 3.4 & 9.0 & 4.2 & 9.0 \\
\hline
\end{tabular}

Notes: a. Annualised. b. Constructed over 1967-2017.

Sources: St. Louis Federal Reserve, FRED, CAPUTLB50001SQ, CUMFNS, CAPUTLGMFDS, CAPUTLHITEK2S, CAPUTLG337S, CAPUTLG333S, CAPUTLG331S, CAPUTLGMFNS, CAPUTLG311A2S, CAPUTLG316S, CAPUTLG2211A2S, CAPUTLG21S.

A long-run average trend in the utilisation rate could be consistent with an exogenously determined normal utilisation rate, and also with firms continuously adjusting capacity to obtain a normal degree of capacity utilisation, and yet there is no congruence between the trend average utilisation rate and the normal utilisation rate. In this view the existence of a trend in the long-run average utilisation rate may provide evidence, not of endogeneity in the normal utilisation rate, but of the strength of accelerator mechanisms. ${ }^{22}$ In either interpretation the forces generating long-run Harrodian instability seem to be weaker than suggested by proponents.

We will now offer some remarks on the claim that the Fed's index of capacity utilisation is constructed to be stationary. Nikiforos $(2016$, p. 446) invites the reader to put themselves 'in the shoes of a plant manager who answers the [SPC] questionnaire'. A firm that switches its normal shift system to a double-shift is assumed to produce double the amount of output than it did on a single-shift. 'If after a few years the demand for the products of the firm permanently decreases and the manager decides to drop the second shift, we will be back to the original situation' (ibid.). The permanent decrease in demand is not just abnormally long (that is, a few years vis-à-vis the typical recession of a few quarters), it is also abnormally severe (that is, a 50 per cent contraction). Protracted macro shocks of the sort required to produce significant downward variability in

22. Setterfield (2019) also arrives at the conclusion that accelerator mechanisms are comparatively weak, albeit through different logic. He supposes the existence of a range for $u$ wherein firms would not deem that any change to their investment response is required. This range of theorised inertia is operationalised in data for US manufacturing firms over 1990-2007 using the HP-filtered long-run trend adjusted by the standard deviation for $u$ either side. Note that the methodology does not provide any direct indication to firms' investment response. 
the normal shift system do not occur often in practice. ${ }^{23}$ Greece may be a recent example. And it is Greece where Nikiforos (2018, p. 10) believes that 'one shift is the new normal utilization rate' (emphasis in the original). Some industries have minimal or no variability in the normal shift system. ${ }^{24}$ Even for pure assemblers there are margins of adjustment besides changing the normal shift system, for example the number of hours and the number of workers on each shift. One would also expect that the bulk of the adjustment to a 50 per cent permanent decrease in demand would be a comparable decline in fixed investment and higher exit rates for firms and establishments. ${ }^{25}$

Another difficulty is that Nikiforos $(2013 ; 2016)$ considers the choice of normal shift system to be of analogous importance to, and entwined with, the choice of technique. Assuming that the 50 per cent permanent decline in demand over a few years does not bankrupt the cash-strapped entrepreneur, it is doubtful that she would be willing or able to make the large capital outlays required to change the production technique (and normal shift system). And it would only be the cost-minimising decision to do so if the permanent decline in demand was literally expected to be permanent (or else additional capital outlays would be duplicated in order to change the system back). A final point is that if there was significant downward variability in the normal shift system due to effective demand pressures then the long-run trend in the AWC would need to resemble the Fed's indexes of capacity utilisation.

\section{CONCLUSION}

Recent literature has reconsidered the case for endogeneity in the normal rate of capacity utilisation. The new approach proposes a new definition of capacity utilisation as the average workweek of capital. There are shortcomings with the unconventional definition. Variability in the normal shift system is industry-specific. Shiftwork does exhibit pro-cyclical variations. Although the upward trend in the average workweek of capital appears to be driven more by structural determinants than pressures on the demand side. Overall our findings suggest caution on the new approach.

The finding of a significant downward trend in the Fed's indexes of capacity utilisation since the mid 1960s requires tentative conclusions. The positive relation between the trend average utilisation rate and the growth rate of aggregate demand would appear to provide some support to the old approach. Combining endogeneity in the normal utilisation rate with an SSM adjustment mechanism, as Nah and Lavoie (2018) do in a

23. An emphasis is placed on normal to highlight that cyclical deviations in the number of shifts a plant operates need not imply changes to the normal shift system. A pure assembler could run a triple-shift system infrequently at full capacity, a double-shift under normal demand conditions and a single-shift infrequently in recessions.

24. Mattey and Strongin (1997) report that continuous processors respond to negative demand shocks, not by altering the number of shifts, but by closing the plant for longer during a quarterly interval (for example, weeks instead of days). The long-run adjustment to permanently lower demand would involve less fixed investment and less employment without any change to the number of shifts that the plant operates when open (or to its normal shift system).

25. We also note the possibility of an entrepreneur having two plants with the technology of pure assemblers. Supposing a demand shock forces both plants to run single-instead of double-shifts, and absent an improvement in demand prospects, the entrepreneur would eventually permanently close one of the plants (and liquefy its assets). The remaining plant would then be returned to operating on its normal double-shift system. Higher exit rates for the most underutilised firms and establishments would push up the Fed's $u$ along with the AWC. 
model that explores overhead labour, may not please everyone but may have some empirical support. Alternatively, for those who doubt that the trend average utilisation rate can give reliable insight into the normal utilisation rate, then the downward trend may be an indicator of comparatively weak accelerator mechanisms. Whatever the case, it remains that attempts by firms to adjust capacity to the level of effective demand is an important part of the cyclical adjustment to significant and sustained deviations in utilisation rates. There is strong evidence in US data to support a driving role for what the SSM authors refer to as autonomous non-capacity-generating expenditures or what Fiebiger and Lavoie (2019) refer to as Kalecki/Luxemburg 'external markets'.

Literature on demand-determined SSM models has expanded in recent years. The case for developing supply-determined Marx/Harrod models based on Goodwinian profitsqueeze mechanisms is much less compelling. Empirical support is typically asserted on the basis of a pro-cyclical profit share. Fiebiger (2018) reports evidence of recurrent pseudo-Goodwin cycles in post-World War II US business cycles, in particular, corporate profits has a closer contemporaneous relation with household fixed investment and debt-financed consumption than with corporate fixed investment. Further, unless one wants to echo naïve orthodox conclusions, integrating the supply side does not imply that the labour market in a mature economy must always be a binding constraint on growth. As put by Fazzari et al. (2018, p. 22), 'there is an empirically relevant range of growth rates of demand that induce supply growth to adapt to demand growth, reversing the direction of causation of mainstream macro growth theory'.

The SSM authors are not the first to ask readers to assume the existence of a portion of effective demand that is unrelated to the current cyclical position. Keynes and Kalecki did (and so did Harrod in his long-range capital outlay). We mention this as some criticisms of the SSM approach appear largely misdirected. Nikiforos (2018, p. 17, fn 15) remarks on Fiebiger and Lavoie (2019) who refer to semi-autonomous expenditures: 'the prefix "semi" makes a world of difference here'. Using the prefix of 'semi' may make it more obvious that "autonomous" need not mean "exogenous" or "constant" ... . To apply the message of our model empirically is to explore how autonomous demand evolves in particular historical periods' (Fazzari et al. 2018, p. 24). Still, it would be odd to deem that an approach is validated or otherwise depending on a prefix to clarify obviousness. No doubt the financial sphere presents many complexities that could be further explored, yet not all paths must lead to Greece (Nikiforos 2018, p. 10, 12-13). ${ }^{26}$ And whatever real financial interactions are explored, the causal nexus emphasised by the SSM -running from (semi-) autonomous non-capacitygenerating expenditures to induced capacity investment - would seem pertinent to arriving at an informed policymaking message.

\section{REFERENCES}

Beaulieu, J.J. and J. Mattey (1998), 'The workweek of capital and capital utilization in manufacturing', Journal of Productivity Analysis, 10(2), 199-223.

26. As one example Nikiforos (2018, p. 12) argues that '[a] careful reader with some basic knowledge of Greece's political economy will object to the previous argument: government expenditure will not return autonomously to its pre-crisis growth rate'. One would think that the SSM position would be contradicted if Greece had experienced a depression despite a large increase in government expenditures (not because of Troika-imposed fiscal austerity). 
Caserta, M. and V. Chick (1997), 'Provisional equilibrium and macroeconomic theory', in P. Arestis, G. Palma and M.C. Sawyer (eds), Markets, Employment and Economic Policy: Essays in Honour of G.C. Harcourt, Vol. 2, London: Routledge, pp. 223-237.

Corrado, C. and J. Mattey (1997), 'Capacity utilization', Journal of Economic Perspectives, $11(1), 151-167$.

Dallery, T. and T. van Treeck (2011), 'Conflicting claims and equilibrium adjustment processes in a stock-flow consistent macroeconomic model', Review of Political Economy, 23(2), 189-211.

Dávila-Fernández, M.J., J.L. Oreiro and L.F. Punzo (2019), 'Inconsistency and over-determination in neo-Kaleckian growth models: a note', Metroeconomica, 70(20), 313-319.

Doyle, M.P. (2000), 'The 1989 change in the definition of capacity: a plant-level perspective', Working Paper No CES-WP-00-09, US Census Bureau Center for Economic Studies.

Dutt, A.K. (1997), 'Equilibrium, path dependence and hysteresis in post-Keynesian models', in P. Arestis, G. Palma and M. Sawyer (eds), Capital Controversy, Post-Keynesian Economics and the History of Economic Thought: Essays in Honour of Geoff Harcourt, London: Routledge, pp. 238-253.

Fazzari, S., P. Ferri and A.M. Variato (2018), 'Demand-led growth and accommodating supply', FMM Working Papers No 15, Macroeconomic Policy Institute.

Fiebiger, B. (2018), 'Semi-autonomous household expenditures as the causa causans of post-war US business cycles: the stability and instability of Luxemburg-type external markets', Cambridge Journal of Economics, 42(1), 155-175.

Fiebiger, B. and M. Lavoie (2019), 'Trend and business cycles with external markets: non-capacity generating semi-autonomous expenditures and effective demand', Metroeconomica, 70(2), 247-262.

Foss, M.F. (1981a), Changes in the Workweek of Fixed Capital: US Manufacturing, 1929 to 1976, Washington, DC: American Enterprise Institute for Public Policy Research.

Foss, M.F. (1981b), 'Long-run changes in the workweek of fixed capital', American Economic Review, 71(2), 58-63.

Foss, M.F. (1984), Changing Utilization of Fixed Capital: An Element in Long-Term Growth, Washington, DC: American Enterprise Institute for Public Policy Research.

Foss, M.F. (1995), 'Operating hours of the US manufacturing plants, 1976-1988, and their significance for productivity change', in D. Anxo, G. Bosch, G. Cette, T. Sterner and D. Taddei (eds), Work Patterns and Capital Utilisation, London: Kluwer Academic Publishers, pp. 281-309.

Freitas, F. and F. Serrano (2015), 'Growth rate and level effects: the adjustment of capacity to demand and the Sraffian supermultiplier', Review of Political Economy, 27(3), 257-281.

Girardi, D. and R. Pariboni (2019), 'Normal utilization as the adjusting variable in neo-Kaleckian growth models: a critique', Metroeconomica, 70(2), 341-358.

Gorodnichenko, Y. and M.D. Shapiro (2011), 'Using the survey of plant capacity to measure capital utilization', Working Paper No CES-WP-11-19, US Census Bureau Center for Economic Studies.

Hein, E., M. Lavoie and T. van Treeck (2012), 'Harrodian instability and the "normal rate" of capacity utilization in Kaleckian models of distribution and growth: a survey', Metroeconomica, 63(1), 139-169.

Kurz, H. (1986), “'Normal” positions and capital utilization', Political Economy: Studies in the Surplus Approach, 2(1), 37-54.

Lavoie, M. (1995), 'The Kaleckian model of growth and distribution and its neo-Ricardian and neo-Marxian critiques', Cambridge Journal of Economics, 19(6), 789-818.

Lavoie, M. (2016), 'Convergence towards the normal rate of capacity utilization in neo-Kaleckian models: the role of non-capacity creating autonomous expenditures', Metroeconomica, 67(1), 172-201.

Lavoie, M. (2019), 'Inconsistencies in the note of Dávila-Fernández, Oreiro and Punzo', Metroeconomica, 70(20), 320-324.

Mattey, J. and S. Strongin (1997), 'Factor utilization and margins for adjusting output: evidence from manufacturing plants', Federal Reserve Bank of San Francisco Economic Review, 2, 3-17. 
Mayshar, J. and G. Solon (1993), 'Shift work and the business cycle', American Economic Review: Papers and Proceedings, 83(2), 224-228.

Morin, N. and J. Stevens (2004), 'Estimating capacity utilization from survey data', Finance and Economics Discussion Paper No 2004-49, Board of Governors of the Federal Reserve System.

Nah, W.J. and M. Lavoie (2018), 'Overhead labour costs in a neo-Kaleckian growth model with autonomous expenditures', IPE Working Papers No 111/2018, Berlin School of Economics and Law, Institute for International Political Economy.

Nikiforos, M. (2012), 'On the "utilization controversy": a theoretical and empirical discussion of the Kaleckian model of growth and distribution', Working Paper No 739, Levy Economics Institute, Annandale-on-Hudson, NY.

Nikiforos, M. (2013), 'The (normal) rate of capacity utilization at the firm level', Metroeconomica, 64(3), 513-538.

Nikiforos, M. (2016), 'On the "utilisation controversy": a theoretical and empirical discussion of the Kaleckian model of growth and distribution', Cambridge Journal of Economics, 40(2), 437-467.

Nikiforos, M. (2018), 'Some comments on the Sraffian Supermultiplier approach to growth and distribution', Working Paper No 907, Levy Economics Institute, Annandale-on-Hudson, NY.

Orr, J.A. (1989), 'The average workweek of capital in manufacturing, 1952-1984', Journal of the American Statistical Association, 84(405), 88-94.

Palumbo, A. and A. Trezzini (2003), 'Growth without normal capacity utilization', European Journal of the History of Economic Thought, 10(1), 109-135.

Pariboni, R. and D. Girardi (2018), 'A(nother) note on the inconsistency of neo-Kaleckian growth models', Centro Sraffa Working Papers No 31, May.

Pierce, J. and E. Wisniewski (2018), 'Some characteristics of the decline in manufacturing capacity utilization', FEDS Notes, 1 March, Board of Governors of the Federal Reserve System.

Setterfield, M. (2019), 'Long-run variation in capacity utilization in the presence of a fixed normal rate', Cambridge Journal of Economics, 43(2), 443-463.

Shapiro, M.D. (1986), 'Capital utilization and capital accumulation: theory and evidence', NBER Working Paper No 1900.

Shapiro, M.D. (1996), 'Macroeconomic implications of variation in the workweek of capital', Brookings Papers on Economics Activity, 2, 79-133.

Skott, P. (2012), 'Theoretical and empirical shortcomings of the Kaleckian investment function', Metroeconomica, 63(1), 109-138.

Skott, P. (2019): 'Autonomous demand, Harrodian instability and the supply side', Metroeconomica, 70(2), 233-246.

Skott, P. and B. Zipperer (2011), 'Cyclical patterns of employment, utilization, and profitability', Journal of Post Keynesian Economics, 34(1), 25-57.

Skott, P. and B. Zipperer (2012), 'An empirical evaluation of three post-Keynesian models', European Journal of Economics and Economic Policies: Intervention, 9(2), 277-308.

Smith, M. (2012), 'Demand-led growth theory: a historical approach', Review of Political Economy, 24(4), 543-573.

Spence, A.M. (1977), 'Entry, capacity, investment and oligopolistic pricing', Bell Journal of Economics, 8(2), 534-544.

Taubman, P. and P. Gottschalk (1971), 'The average workweek of capital in manufacturing', Journal of the American Statistical Association, 66(335), 448-455.

Trezzini, A. (1998), 'Capacity utilisation in the long run: some further considerations', Contributions to Political Economy, 17(1), 53-67. 